\title{
CARTA DA EDUCAÇÃO PENITENCIÁRIA AMAPAENSE ${ }^{12}$
}

\author{
Myryan Sylvia Sousa de Almeida \\ Emerson de Paula Silva \\ Eliane Leal V asquez.
}

\section{Aos Órgãos dos Poderes Executivo, Judiciário e Legislativo}

Prezados Gestores,

As discussões acerca da temática Educação Penitenciária na Universidade Federal do Amapá iniciaram-se em 2012, com a criação da linha de pesquisa: Políticas Públicas para Educação Penitenciária, no Grupo Políticas Públicas e Educação Inclusiva (GPPEI/UNIFAP/CNPq), instituído pela professora Leila do Socorro Rodrigues Feio, o que ocorreu a partir do ingresso da professora Eliane Leal Vasquez no Curso Intercultural Indígena/Campus Norte do Oiapoque (UNIFAP), momento em que foi cadastrado o projeto de pesquisa: Políticas Públicas para Educação Penitenciária: Pela implantação de um programa governamental, por intermédio do Curso de Pedagogia, no Campus Marco Zero do Equador.

Em 2013, foi realizado o I Seminário de Políticas Públicas para Educação Penitenciária no Amapá, através de um projeto de extensão, o qual contou com a participação de 170 pessoas.

O evento foi idealizado, a partir da articulação entre alguns membros da II Comissão para elaboração do Plano Estadual de Educação para o Sistema Penitenciário Amapaense, com pesquisadores do GPPEI e apoio logístico do Núcleo de Acessibilidade e Inclusão (NAI/PROEAC/UNIFAP). No referido evento foram realizadas três oficinas com os participantes, com o objetivo de discutir as concepções filosóficas de educação para o Plano Estadual de Educação para o Sistema Penitenciário Amapaense (PEESP-AP), onde se deliberou que a educação penitenciária, mesmo não sendo uma modalidade de ensino reconhecida no Brasil, a sua concepção fundamentava-se em cinco pilares: Direi-

\footnotetext{
${ }^{1}$ DOI: $10.29388 / 978-65-86678-21-5-f .141-146$.

${ }^{2}$ Esta carta foi redigida e aprovada de forma coletiva, em 27 de março de 2018, no III Seminário de Políticas Públicas para a Educação Penitenciária no Amapá: Arte, Cultura e Educação Penitenciária, pelos participantes do Grupo de Trabalho: Criação Coletiva de Documento Público sobre a implantação de Políticas Públicas de Cultura na Educação Penitenciária
} 
tos Humanos, Cidadania, Direito Social, Cultura de Paz e Inclusão Social, o que contribui para a elaboração da primeira versão completa do documento, já no ano de 2014.

A UNIFAP continuou em 2015, os debates sobre a educação penitenciária no Estado do Amapá, realizando o II Seminário de Políticas Públicas para Educação Penitenciária no Amapá: Articulando a consolidação das metas do Plano Estadual de Educação para o Sistema Penitenciário Amapaense na política educacional, o qual mais uma vez, foi realizado como um projeto de extensão, onde se reuniram em torno de 100 pessoas interessadas no projeto de extensão. Este visava debater sobre a implementação do Plano Estadual de Educação para o Sistema Penitenciário Amapaense, já que até novembro de 2015, a Secretaria de Estado da Educação - SEED, não tinha tomado providências para encaminhamento do Plano aos órgãos, como a Assembleia Legislativa do Estado do Amapá, com o fim de aprovação deste através de um projeto de lei.

Há de se considerar que o Conselho Estadual de Educação - CEE, ligado ao GEA/SEED, aprovou também a Resolução no 057/2015-CEE/AP, que dispõe sobre a oferta da educação de jovens e adultos e da educação profissional e tecnológica para pessoas privadas de liberdade no Estado do Amapá, como resultado das demandas, que aos poucos passam a ser inseridas na política educacional amapaense, em decorrência da legislação mais recente da área.

No período de 23 a 27 de março de 2018, realizou-se o III Seminário de Políticas Públicas para Educação Penitenciária, organizado pelo Curso de Teatro - CCT/UNIFAP e pelo Núcleo de Acessibilidade e Inclusão - NAI/ PROEAC/UNIFAP, onde estiveram aproximadamente 120 participantes entre professores, educadores penitenciários, técnicos, professores da Escola Estadual São José - EESJ/SEED, estudantes, pesquisadores da Universidade Fedral do Amapá, Universidade Federal da Bahia, Universidade do Estado de Santa Catarina - UESC, Museu de Arte Moderna de São Paulo - MAM e outras IFEs. Além de educadores penitenciários que trabalham no Instituto de Educação Penitenciário do Amapá - IAPEN/SEJUSP e demais membros da sociedade amapaense.

Considerando a mais recente legislação brasileira, que normatiza a educação em estabelecimentos penais, além de outras que tratam da educação e cultura, como:

- Plano Nacional de Cultura e o Sistema Nacional de Cultura;

- Plano Estratégico de Educação no âmbito do Sistema Prisional;

- Plano Nacional de Educação; 
- Plano Estadual de Educação;

- Plano Estadual de Educação para o Sistema Penitenciário Amapaen se;

- Plano Estadual de Cultura do Amapá;

- Resolução no 2/2010 de 19 de maio de 2010;

- Decreto no 7.626 de 24 de novembro de 2011;

- Recomendação no 44/13 de 26 de novembro de 2013;

- Resolução no 057/2015-CEE/AP;

- Art. 13 da Resolução no 39/2017 de 29 de novembro de 2017-CON SU/UNIFAP.

Por meio deste documento do III SPPEP/AP, que nomeamos de Carta da Educação Penitenciária Amapaense, requeremos que a mesma seja encaminhada oficialmente aos órgãos locais do Estado de Amapá para ciência, tanto do Poder Executivo, Judiciário e Legislativo para devidas providências, em especial, ao Ministério Público do Estado do Amapá, à Secretaria de Estado da Educação, à Vara de Execução Penal do Tribunal de Justiça do Amapá e Secretaria de Segurança e Justiça do Amapá, bem como à Pastoral Carcerária e à Comissão de Direitos Humanos da Ordem dos Advogados do Estado do Amapá, visando que o Estado do Amapá se torne colaborador da implementação do Plano Estratégico de Educação para o Sistema Prisional, instituído pelo Decreto $\mathrm{n}^{\circ}$ 7.626 de 24 de novembro de 2011.

Afinal, de que vale termos um Plano Estadual de Educação para Sistema Penitenciário Amapaense - PEESP-AP, elaborado e atualizado a sua última versão em $2017^{3}$, sob a articulação da gestora e professores, com apoio do Núcleo de Acessibilidade e Inclusão - NAI/UNIFAP, se a política educacional à população carcerária ainda não se implementou de fato?

De acordo com PEESP-AP (AMAPÁ, 2017), as metas prioritárias a serem atendidas são:

Meta I - Ampliação da matrícula de educação formal;

Meta II - Ampliação da oferta de educação não formal;

Meta III - Ampliação de oferta de qualificação profissional;

Meta IV - Ampliação no número de inscritos nos exames de certifica ção;

Meta V - Ampliação no número de bibliotecas e de espaços de leitura;

${ }^{3}$ AMAPÁ. Plano Estadual de Educação para o Sistema Penitenciário Amapaense. Macapá, 2017. 
Meta VI - Melhoria na qualidade da oferta de educação.

Há de se condiserar que para atingir parcialmente ou integralmente as metas do PEESP-AP, faz-se necessário um planejamento integrado, que conte com a articulação e termos de colaboração técnico entre as instituições e os órgãos envolvidos de forma direta e indireta com as demandas da educação penitenciária, bem como um conjunto de ações prioritárias, a saber:

- Instituir uma Comissão pela Reitoria da UNIFAP para tratar das demandas para a formação da comunidade escolar-prisional, bem como para assessorar a implementação de políticas para a educação penitenciária no Estado do Amapá;

- Criar a disciplina de Educação Penitenciária nos cursos de licenciaturas da UNIFAP;

- Implementar parte diversificada do currículo escolar, tomando como referência a base nacional comum para comtemplar as peculiaridares dos estudantes privados de liberdade;

- Criar reserva de vagas para curso de graduação presencial na UNIFAP para egressos do sistema penitenciário e de pessoas que estão no regime aberto e semiaberto;

- Criar a resolução no âmbito local à Educação Especial, para cursos ofertados pela Educação de Jovens e Adultos na Educação Penitenciária, pois a Resolução No 057/2015 não contempla as demandas recorrentes da Educação Especial e do atendimento educacional especializado;

- Ampliar os projetos de extensão da UNIFAP, que tem a população carcerária e os profissionais que trabalham no ambiente carcerário como público;

- Planejar e implementar o projeto de extensão da UNIFAP, tendo as mulheres encarceradas e seus filhos/filhas como público;

- Articular, planejar e implantar uma proposta curricular específica para Educação Penitenciária para o Estado do Amapá, com educação semipresencial ou ofertada por módulos;

- Adequar os aspectos formais (registro da frequência, tempo de aula e currículo) e outros aspectos pedagógicos, referentes ao funcionamento das escolas em contexto de privação da liberdade, com o fim de garantir que o funcionamento das unidades escolares dialoguem com o calendário escolar oficial da SEED; 
- Cumprir a Portaria no âmbito do IAPEN/SEJUSP, que trata do posto fixo de funcionamento de segurança dos profissionais da educação, que trabalham no ambiente carcerário;

- Manutenção por via UNIFAP da realização do Seminário de Políticas Públicas para Educação Penitenciária nos anos futuros;

- Promover a reflexão sobre educação profisional nas escolas em contexto de privação de liberdade;

- Articular, planejar e implementar critérios para atuação de gestores, técnicos e professores que trabalham nas escolas em contexto de privação de liberdade, como o processo seletivo interno, a avaliação psicológica e a formação acadêmica ou continuada na Educação Penitenciária ou áreas afins.

- Fortalecer o trabalho da Coordenadoria do Tratamento Penal - COTRAP/IAPEN, por meio da firmação de termo de cooperação técnico, e outras, com o fim de captar recursos financeiros para planejar, implementar e avaliar a execução de projetos e ações institucionais, tendo como público alvo, os servidores penitenciários, profissionais da educação e a população carcerária.

Nós, os participantes do III Seminário de Políticas Públicas para Educação Penitenciária, avaliamos ser de extrema importância a implentação de ações institucionais e projetos com foco nas metas do PEESP-AP, pois o acesso à educação e cultura promovem o desenvolvimento integral do ser humano e auxilia nas relações interpessoais dentro e fora da prisão, além de ser imprescendível para tentar acessar o mercado formal de trabalho.

Assim, compreendemos que atender às demandas da Educação Penitenciária implica em ofertar com qualidade os serviços prestados à população carcerária e garantir as condições de trabalho aos servidores, que trabalham com eles, e ao mesmo tempo, numa visão de futuro, é pensar na sociedade amapaense, onde o acesso à educação e cultura são entendidos como direito humano.

Macapá, 27 de abril de 2018. 
